\title{
Biopsy and post-mortem findings in a patient receiving cerebellar stimulation for epilepsy
}

\author{
GDS WRIGHT, RO WELLER \\ From the Wessex Neurological Centre and Department of Neuropathology, Southampton General Hospital, \\ Southampton, UK
}

SUMMARY Cerebellar stimulating equipment was implanted in a 24-year-old male with severe epilepsy. He received continuous alternating stimulation for at least two months, intermittent bilateral stimulation on demand for at least two months and numerous short bursts of stimulation during preliminary testing and calibration of the apparatus. The patient died during a prolonged grand mal seizure 16 months after implantation and this paper reports the findings at necropsy. A special study was made of the degree of tissue damage in the cerebellar hemispheres resulting from implantation of the electrodes and subsequent cerebellar stimulation. There was deep grooving of the upper aspect of the cerebellum under the electrodes but only a minor degree of neuronal loss and gliosis was observed in the underlying cortex. Purkinje cell populations in the cerebellum at necropsy were similar to those in a biopsy specimen taken 16 months previously during implantation. The electrodes were covered with a thick layer of fibrous tissue but they were not adherent to the cerebellar surface. Thus, the main significant findings in the present case were the very slight structural damage to the cerebellum in contact with the electrodes and the intense fibrosis around the electrodes themselves. These features are discussed in relation to the efficacy of long-term cerebellar stimulation.

Cerebellar stimulation has been recommended as a useful treatment in severe epilepsy and in a variety of motor disorders. ${ }^{12}$ There is, however, still considerable uncertainty about the degree of tissue damage caused by implantation of the electrodes and by chronic electrical stimulation of the cerebellum. ${ }^{3}$ Although the study of a number of human and animal brains has shown that pathological changes can occur with cerebellar stimulation, firm criteria have not yet been determined to enable optimal parameters for cerebellar stimulation to be defined. ${ }^{3}$

There are only a few reports of post-mortem studies in patients who have received cerebellar stimulation. ${ }^{24-9}$ The present paper is a post-mortem study of a 24-year-old male with severe epilepsy who died 16 months after the implantation of cerebellar electrodes. Electrode access resistance was measured at implantation and the stimulating

Address for reprint requests: Dr GDS Wright, Department of Neurology, St James's University Hospital, Beckett Street, Leeds LS9 7TF, UK.

Received 16 July 1982

Accepted 4 October 1982 equipment was accurately calibrated. The functioning of the stimulating equipment was regularly reviewed and reasonable estimates of the charge density at the cerebellar surface and the total charge delivered to the cerebellum are therefore available.

\section{Case history}

The patient, (SB, born 8/1/55), was 24 years old at the time of his admission to the Southampton cerebellar stimulation trial. His epilepsy began at the age of seven years and there were no predisposing factors. He suffered from grand mal epilepsy, complex partial epilepsy and petit mal epilepsy. The grand mal attacks occurred rarely, but could be severe and prolonged. Complex partial attacks occurred up to five times a day and the petit mal attacks up to forty or more in a day. Medication consisted of phenytoin $200 \mathrm{mg}$ twice daily and carbamazepine $200 \mathrm{mg}$ four times a day and he had been on this combination for over six months before admission. It was considered the best combination and the optimal dosage and gave serum levels of phenytoin $1.3 \mathrm{mg} / 100 \mathrm{ml}$ and carbamazepine $0.7 \mathrm{mg} / 100 \mathrm{ml}$. Previously he had, at different times, been treated with these drugs in different dosages and with primidone.

At operation on 20 March 1979 under general anaesthesia, two eight-button electrode pads with an electrode surface area $32 \mathrm{~mm}^{2}$ (Avery Laboratories Inc) were placed 
on the upper surface of the cerebellum through bilateral enlarged occipital burr holes. They were positioned parasagittally approximately $2 \mathrm{~cm}$ from the mid-line on each side. The electrode leads were taken subcutaneously to two receivers placed in pockets on the anterior chest wall. A biopsy was taken from the left cerebellar hemisphere underlying the burr hole during this operation and showed sporadic loss of Purkinje cells, but no significant gliosis of the molecular layer. The access resistance of the electrodes was measured and the implanted apparatus calibrated before the incisions in the chest wall were closed. ${ }^{10}$ At a current of $5 \mathrm{~mA}$, the right electrode had an access resistance of $640 \Omega$ and the left electrode an access resistance of $460 \Omega$. When the patient had recovered from the operation and the frequency of his fits had returned to their pre-operative level, the first two-month phase of the cerebellar stimulation trial programme was started. At this time, skull radiographs showed that the left cerebellar electrode had moved laterally and was also inverted, and at the end of the phase it was decided to reposition it and recommence the trial. It is not known whether the patient received any stimulation during this initial period as the coding for the trial was not broken and he was reallocated after his second operation. The second operation to reposition the left electrode took place on $18 \mathrm{July,} \mathrm{1979.} \mathrm{The}$ access resistance was not measured on this occasion as only the electrode and the adjacent part of its lead were exposed. As before, when the patient had returned to his pre-operative state the trial was recommenced.

The Southampton trial currently in progress is divided into three phases, each lasting two months. Patients receive two months of contingent stimulation when both electrodes are activated by pressing a button on the stimulator and for two minutes after releasing it; two months of continuous stimulation alternating from one side of the cerebellum to the other every minute; and two months in which there is no stimulation. The sequence of the phases is randomly allocated and the code is not broken until the trial has been completed. Patients are instructed to press the button on the receiver during an aura, if one occurs, or failing that after an attack. Staff members are asked to press it during any attack they observe. These practices are carried out throughout the trial. The patient described in this article received an initial two months of contingent stimulation followed by two months without stimulation and finally two months of continuous alternating stimulation.

The cerebellar stimulator was designed to produce capacitively-coupled pulses of alternating polarity. Throughout the trial it was adjusted to produce a mean peak current of $5 \mathrm{~mA}$ at the cerebellar surface on each side. The rate was set at twenty pulses per second with a pulse width of $500 \mu \mathrm{s}$, and this produced a charge density of $15.6 \mu \mathrm{C} / \mathrm{cm}^{2} /$ phase. The total charge delivered during the period of continuous alternating stimulation was $2.42 \times$ $10^{2} \mathrm{C}$ and although the charge in the intermittent phase and the preliminary trials cannot be estimated accurately it would have been considerably less than during the continuous phase. By the end of the trial, the right electrode would have delivered a greater total charge to the underlying cerebellum since it was in its final position from the start. When all three phases of the trial had been com- pleted, the code was broken and the records of the patient's clinical state in each phase were compared. There was an obvious improvement in his epilepsy during the first phase, contingent stimulation, and this was maintained during the second and third phases. The full clinical results and implications of the trial will be discussed in detail in a subsequent publication. In view of the maintained improvement during the phase when no stimulation took place, another two month period without stimulation was started, unknown to the patient, to assess further any placebo effect. At the end of this period (20 July 1980), the day before he was due to come back to us for assessment, he was found dead by his bed. It is presumed that he died during a prolonged grand mal seizure.

\section{PATHOLOGY}

A necropsy was performed 24 hours after death. The lungs were congested but there was no evidence of inhaled gastric contents or other matter. It was thought that he died from respiratory failure during an epileptic fit. The brain weighed $1500 \mathrm{~g}$ and the cerebral hemispheres were normal externally and on coronal section. No abnormality was seen in the pons or medulla. When the brain was removed



Fig 1 Electrode pads adherent on their superior surfaces to the tentorium cerebelli. The inferior (cerebellar) aspects are covered by vascular fibrous tissue. 


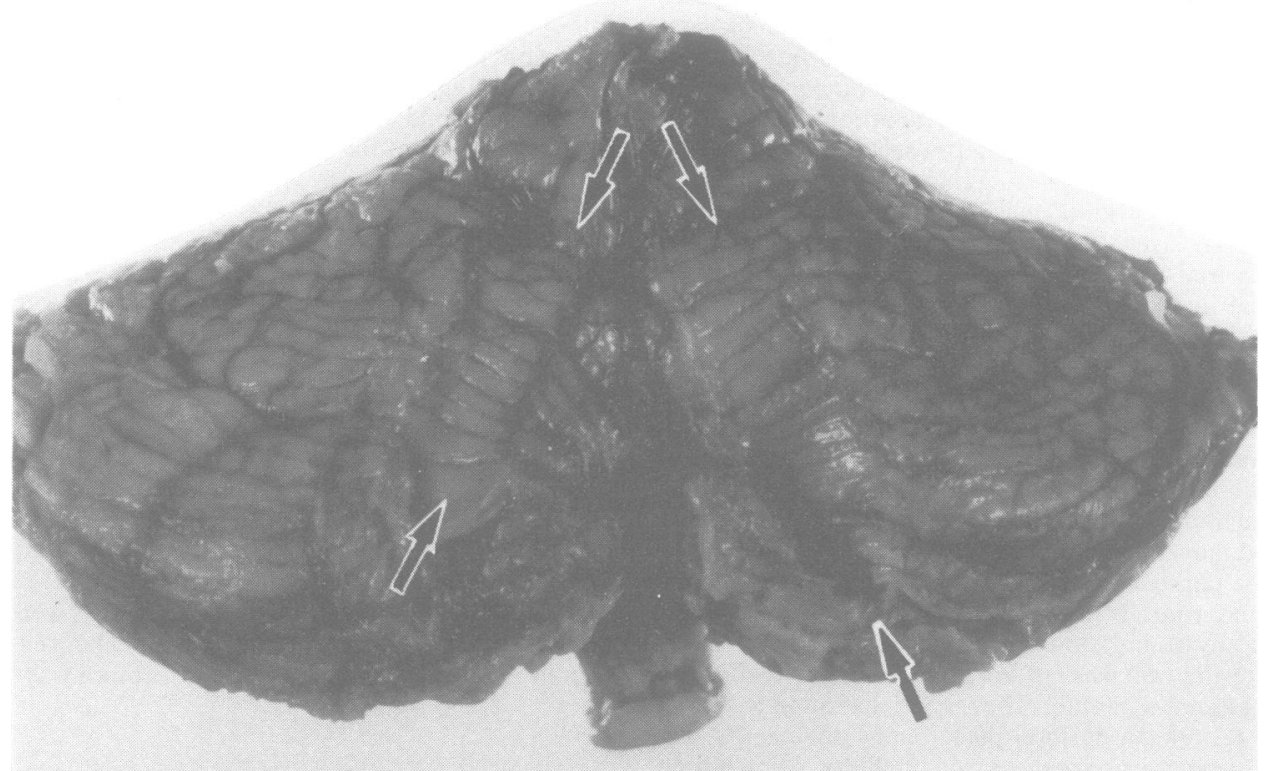

Fig 2 Cerebellum viewed from the back and above showing depression left by the electrodes (arrows).

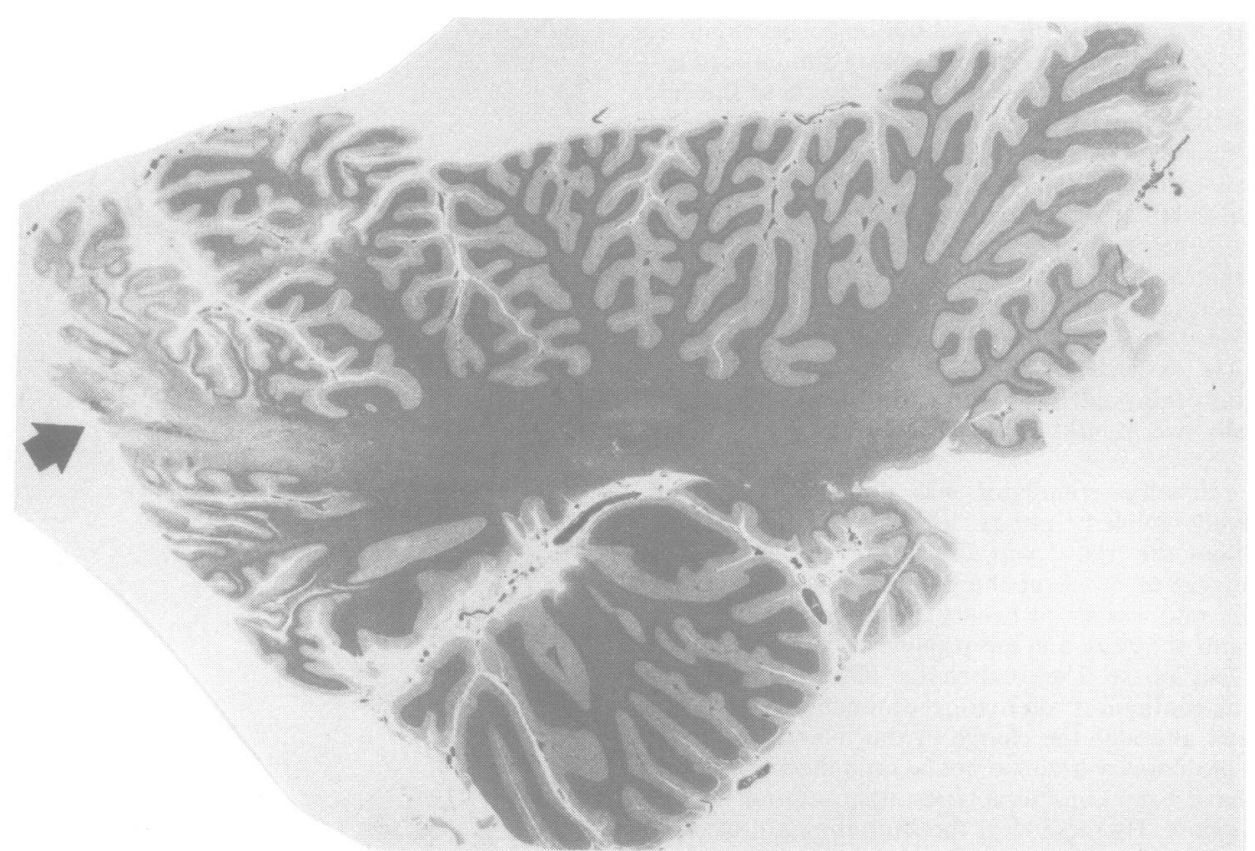

Fig 3 Histological section of the left cerebellar hemisphere. Part of the depression left by the electrode pad is seen on the superior surface; there is no thickening of the arachnoid and no obvious damage to the folia. Posteriorly (arrow) there is damage to the cerebellum at the site of biopsy. 
intact for fixation, the dura and tentorium cerebelli were left attached to it. After fixation, therefore, the tentorium was still in place and the wires attached to the electrodes could be seen piercing the dura on the inferior aspects of both cerebellar hemispheres. The wires were traced upwards and forwards across the posterior borders of the cerebellum and into two electrode pads $60 \mathrm{~mm}$ long $\times$ $10 \mathrm{~mm}$ wide $\times$ approximately $2 \mathrm{~mm}$ thick. Both electrode pads were firmly adherent to the under surface of the tentorium cerebelli and orientated obliquely towards the midline. At the posterior border of the cerebellum, the electrodes were $25 \mathrm{~mm}$ apart and they almost met $(2 \mathrm{~mm}$ apart) at the midline above the superior vermis of the cerebellum. A fibrous membrane coated the whole of the inferior surface of each electrode pad (fig 1). The metal electrode buttons on the right pad were obscured by vascularised fibrous tissue, whereas the electrodes on the left were just visible. Examination of the cerebellum revealed depressions on the superior surface where the electrode pads had been located. There were no adhesions between the electrodes and the cerebellum; furthermore, the arachnoid underlying the electrodes was thin and translucent (fig 2). An area of softened, brown tissue, approximately $2 \mathrm{~cm}$ in diameter, was seen on the posterior surface of the left cerebellar hemisphere towards its medial aspect; the dura

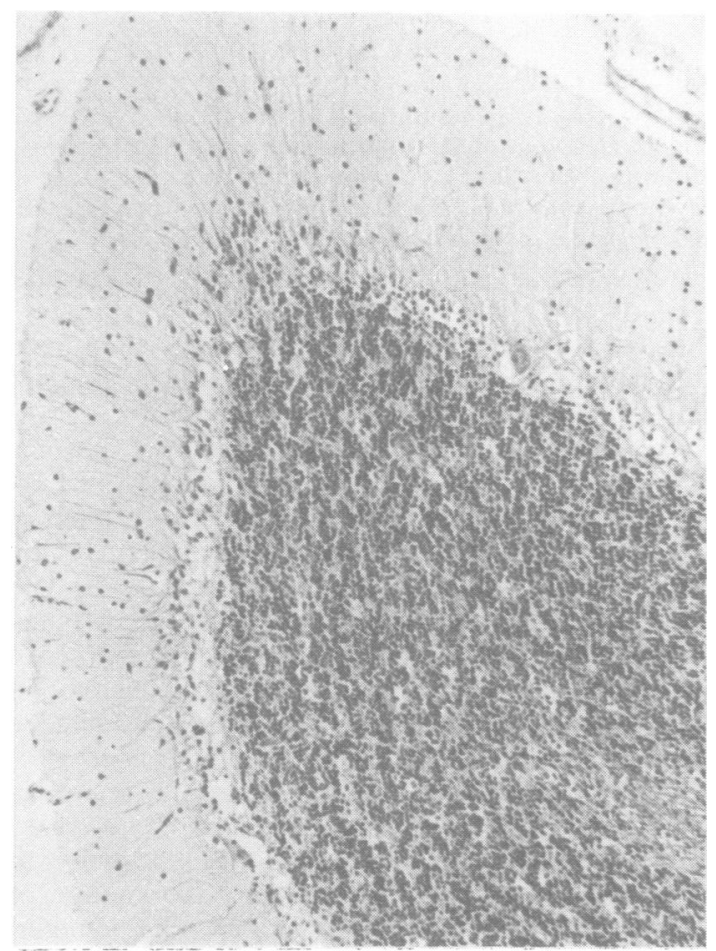

Fig 4 Cerebellar folium in the depression under the electrode illustrated in fig 3, showing loss of Purkinje cells, proliferation of Bergmann glia and reduction in thickness of the molecular layer (left of picture). Mallory's phosphotungstic acid haematoxylin $($ PTAH) $\times 75$. was adherent to the cerebellum at this point from which the biopsy had been taken at the initial operation. Sagittal sections of the cerebellum showed flattening of the folia in the grooves underlying the electrodes but no macroscopic damage (fig 3).

\section{HISTOLOGY OF CEREBELLUM}

Histological examination of the tissue underlying the electodes revealed only very small areas of focal damage to the cerebellar folia. The most severe changes were seen on the left side but still only involved occasional folia. In the damaged areas there was loss of Purkinje cells (fig 4) and a reduction in the thickness of the molecular layer. Astrocyte stains (PTAH) showed an increase in fibrillary glial processes in the molecular layer and proliferation of the Bergmann glia (fig 5). In areas adjacent to the damaged cerebellar cortex, little change could be seen even in areas in contact with the electrodes. No thickening of the arachnoid was observed nor was there any inflammation; the section in fig 6 is taken from the apex of a folium adjacent to that in figs 4 and 5. Apart from the biopsy site at the posterior aspect of the cerebellum, the number of Purkinje cells and the thickness of the molecular layer throughout the cerebellum was similar to that seen in the biopsy taken 16 months previously (fig 7). Histological examination of the hippocampus showed no significant loss of neurons but there was reactive astrocytosis in the end folium. Sections of thalamus, basal ganglia, frontal lobes, mid-brain, pons,

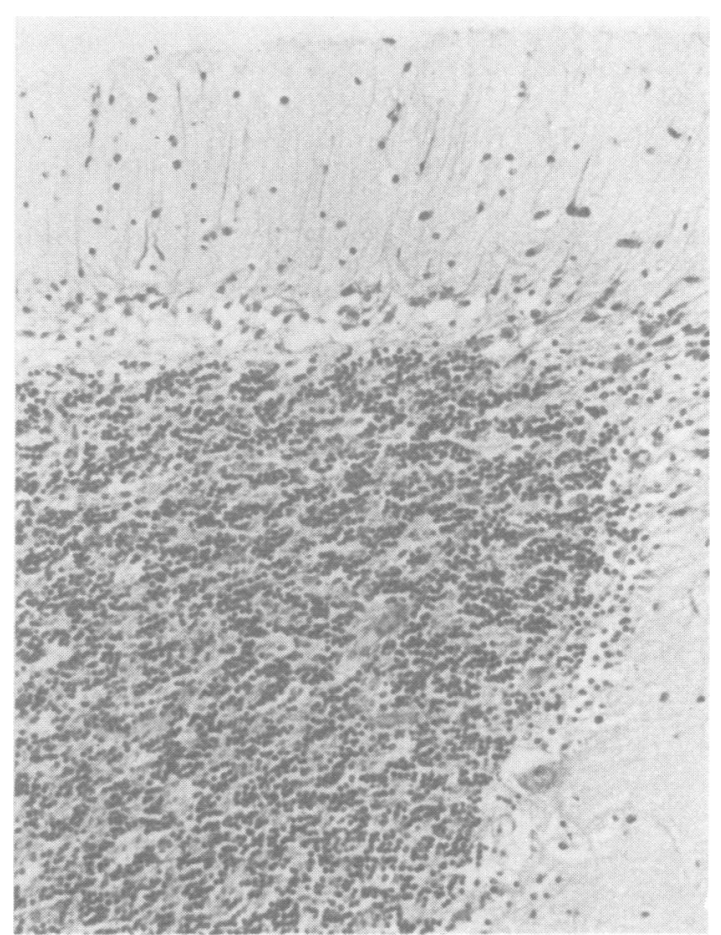

Fig 5 A high power of fig 4 showing gliosis of the molecular layer. PTAH stain $\times 115$. 


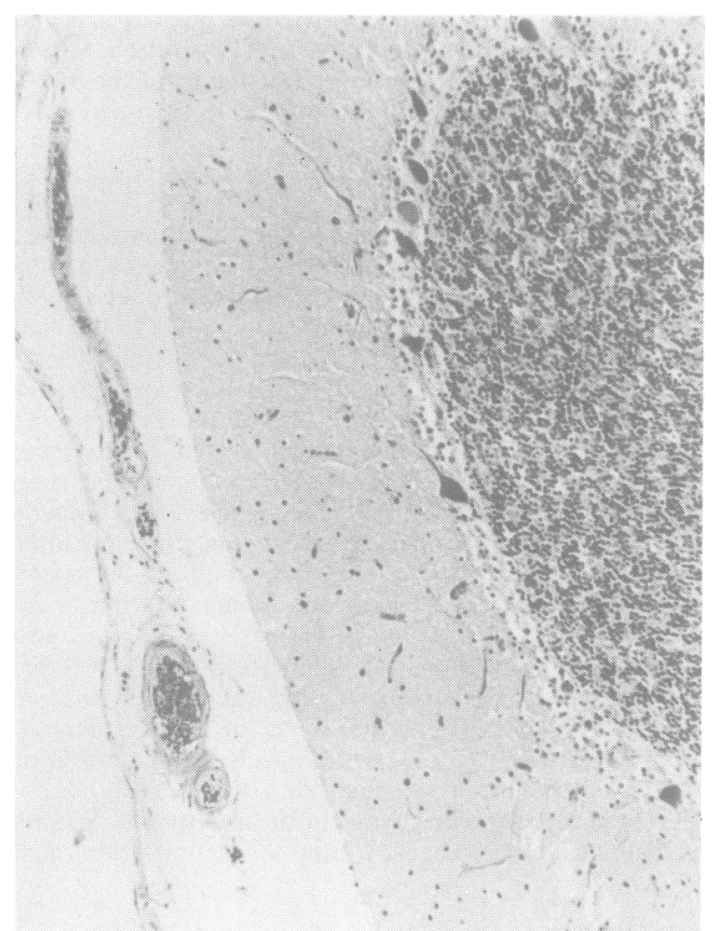

Fig 6 Cerebellar cortex underlying the left electrode pad showing normal arachnoid and little change in the molecular layer of the cerebellum. Purkinje cells are preserved. PTAH stain $\times 75$.

medulla and thoracic cord showed no histological abnormality.

\section{Discussion}

There are several features to be considered when evaluating the pathology associated with cerebellar stimulation in epileptic patients. Biopsies taken at the time of implantation of the electrodes may supply valuable information about the extent of neuronal damage in the cerebellum at the start of stimulation. At necropsy, the degree of fibrosis and tissue reaction around the electrodes may be correlated with the length of time that has elapsed since implantation, with the type of stimulation, and with the functional efficiency of the electrodes. Damage to the cerebellum both from implantation of the electrodes and from stimulation can also be assessed at necropsy and the result compared with previous studies in man and in experimental animals. Such data may be useful in designing cerebellar stimulation programmes in the future.

Although little histological evidence of cerebellar

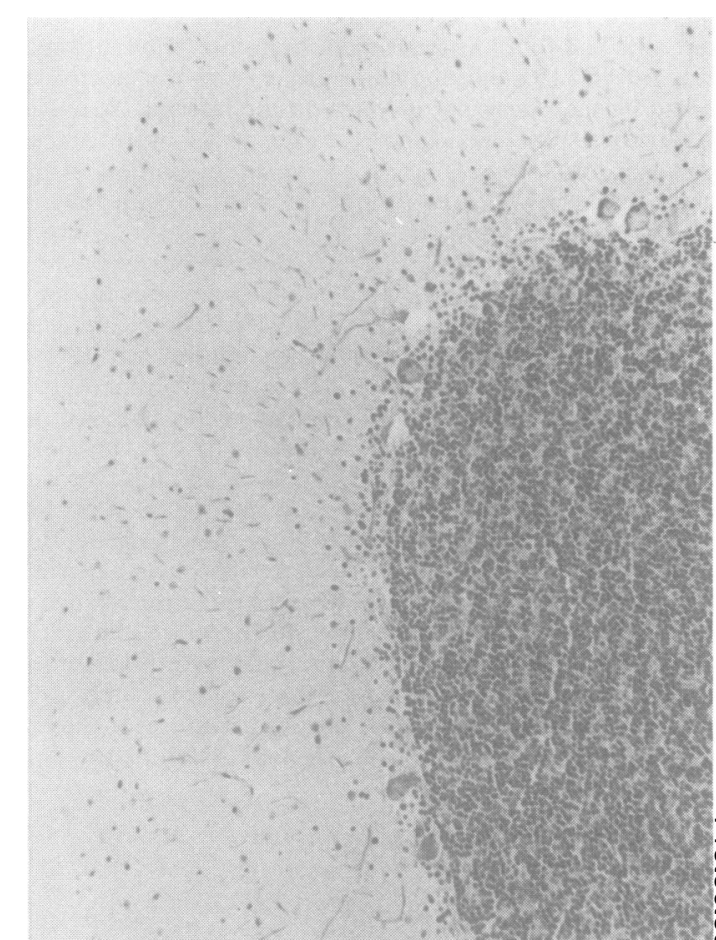

Fig 7 Histology of the original biopsy of the cerebellum showing preservation of Purkinje cells and a molecular layer of normal thickness. Purkinje dendrites can be seen in the molecular layer. PTAH stain $\times 75$.

damage was seen in a biopsy specimen taken from this patient during the initial operation to implant the cerebellar electrodes, neuronal loss with gliosis may be seen in many patients with chronic epilepsy. ${ }^{11}$ Urich et ${ }^{4}{ }^{4}$ reported a reduction of Purkinje cells in the cerebellar biopsies of eleven out of twelve patients with severe epilepsy taken at the time of implantation of cerebellar electrodes. The chief cause of such changes is thought to be hypoxia during prolonged seizures. ${ }^{12}$ However, the effect of anticonvulsant medication cannot be excluded; in particular, phenytoin may cause permanent damage to Purkinje cells. ${ }^{13}$

Fibrous encapsulation of the cerebellar electrodes, as in the present patient, has been described in other epileptics. ${ }^{6}$ However, it does not appear to occur in every case. ${ }^{5}$ Post-mortem examination of two subjects who had undergone cerebellar stimulation for motor disorders showed no encapsulation of the electrodes. ${ }^{4}$ Two out of twelve patients with cerebral palsy, whose electrodes had broken and needed replacement, were found at operation to have fibrous encapsulation of one of the pair of 
stimulating electrodes. ${ }^{2}$ Thickening of the leptomeninges overlying the electrodes occurred in all the monkeys studied by Brown et al, ${ }^{14}$ whether they were stimulated or not. However, the reaction was generally greater around the stimulated electrodes and its intensity was directly related to the charge delivered. All the stimulated electrodes and all but one of the unstimulated electrodes became encapsulated in dense reactive fibrous tissue in another study of cerebellar stimulation in the rhesus monkey. ${ }^{15}$ It appeared to be thickest in those animals that had been implanted for the longest period and thicker around the stimulated electrode.

In the patient described in this report, the right electrode was more thickly encapsulated than the left. This may have been chance, but also may reflect the fact that the right electrode was in situ for sixteen months, whereas the left one had been repositioned and was in its final position for only twelve months. Furthermore, the right electrode had delivered a greater total charge to the cerebellum.

Indentation of the cerebellum by the stimulating electrodes has been described previously in man, ${ }^{256}$ chimpanzees ${ }^{15}$ and rhesus monkeys. ${ }^{14}$ Despite this, there were no adhesions between the electrodes and the cerebellum and the arachnoid underlying the elctrodes appeared thin and translucent in the patient described here. No evidence of macroscopic arachnoid reaction was seen at necropsy in two patients reported by Davis et al. ${ }^{2}$ However, Cooper et $a l^{7}$ described thickening of the arachnoid beneath the electrodes in one of their autopsied epileptic patients and Larson et $a^{9}$ described it in the one patient they examined. An increased reaction, with adhesions between the encapsulated electrode and the underlying cerebellar cortex, was reported in one other case. ${ }^{6}$

Post-mortem histological examination of our patient showed only minor changes in the cerebellum underlying the electrodes. A few very small areas of focal damage were present in cerebellar folia with some loss of Purkinje cells, gliosis and reduction in the thickness of the molecular layer. The left side was more affected and it was on this side that the electrode had been repositioned.

Cooper $e t a l^{5}$ described no changes peculiar to the tissue underlying electrodes in one patient, but in a later paper Cooper $e^{a l^{7}}$ described two further cases where localised lesions beneath the cerebellar electrodes may have occurred. Dow ${ }^{8}$ discusses one patient where unspecified, but mild, change occurred to a limited extent under cerebellar stimulating electrodes. In one patient with motor neuron disease, an area of loss of Purkinje cells and other cells occurred but was confined to the area immediately underlying the electrode. ${ }^{4}$ Robertson et al ${ }^{6}$ de- scribed pathological changes in three patients who had undergone cerebellar stimulation for epilepsy. These consisted of thinning of the molecular layer, loss of granule cells and damage to Purkinje cells and associated interneurons with proliferation of astrocyte glial cells and fibrils. The tissue underlying the caudal part of the electrode, which consisted of silastic membrane only, was more severely affected than tissue underlying the stimulating area of the electrode. Furthermore, the most damaged area of cerebellar cortex was more caudal still, and corresponded to that part of the electrode where the electrode lead originated and was attached to the dura. This was also the region exposed by the craniotomy. Their abnormal findings were localised to the area beneath the implants and involved a very small percentage of the total cerebellar surface. The same authors suggested that there were also pathological changes in the dentate nucleus and in the brain stem. In post-mortem studies of two patients who had received cerebellar stimulation, Davis $e t a l^{2}$ found no histological changes under the electrode buttons, compared to control areas lateral to the pads in the one patient who was stimulated at a charge density of $0.8 \mu \mathrm{C} / \mathrm{cm}^{2} /$ phase. The patient who had received stimulation at charge densities up to $31 \mu \mathrm{C} / \mathrm{cm}^{2} /$ phase, however, had changes in the underlying superficial folia with focal loss of Purkinje cells and granule cells and reactive Bergmann gliosis.

In the human and chimpanzee tissue that they studied, Larson et al $^{9}$ found no evidence of Purkinje cell loss secondary to the application of current. However, they did describe some loss of Purkinje cells beneath the stimulated and unstimulated electrodes which they attributed to mechanical factors. In the monkey, Brown et al ${ }^{14}$ concluded that the mere presence of electrodes leads to pathological changes in the cerebellum. They found thickening of the leptomeninges, attenuation of the molecular layer and loss of Purkinje cells beneath the attenuated layer, but confined to the area immediately beneath the electrode array. Intermittent stimulation tended to increase the amount of damage, but it still remained localised. Charge density appeared to be the important factor with respect to stimulation injury. Similar findings were reported by Dauth $e$ al. ${ }^{15}$ However, when the stimulation was continuous rather than intermittent, there was more widespread damage to Purkinje cells despite the same total charge having been delivered to the cerebellum.

Although the work on rhesus monkeys has been highly informative, its direct translation to the human has been questioned because of the relatively small size of the monkey posterior fossa and the fact that electrodes intended for humans were used. However, there is a growing body of evidence that 
the mere presence of an electrode pad in the posterior fossa will evoke a variety of local pathological changes, including some in the subjacent cerebellar tissue. These may result from operative trauma, haemorrhage, or continuing mechanical damage. Whatever its cause, the pathological change is mild and probably functionally insignificant. However, when stimulation rises above certain levels or is administered continuously, there may be an increase in the degree of damage. ${ }^{3}$ The design of the particular electrode array used may well affect the degree of cerebellar damage, and should be as unobtrusive as possible. The electrode's surface area is a very important factor, and the charge density is directly related to this. Calibration of the implanted equipment and the externally carried apparatus is essential for the correct adjustment of the charge delivered to the cerebellar surface. ${ }^{10} \mathrm{~A}$ physiologically acceptable charge density should be used. ${ }^{314-16}$

In addition to the primary risk of damage to the cerebellum in the patients receiving cerebellar stimulation, any pathological change produced might, by electrode encapsulation and neuronal damage, lessen any therapeutic effect of stimulation. ${ }^{9}$ Dauth et al ${ }^{15}$ described an increase in the access resistance of implanted electrodes with time in the monkeys they examined between seven and thirty-six weeks following implantation. They also found that the access resistance increased still further in those animals undergoing intermittent stimulation but not in those having the same total charge applied continuously. Such a rise in the access resistance would, effectively, lower the current at the cerebellar surface and therefore lower the charge delivered. Babb et al ${ }^{17}$ showed an increase in access resistance of unstimulated electrodes with time, but described an initial decrease in the access resistance during intermittent stimulation and no subsequent rise, despite the electrodes having a similar fibrous tissue reaction surrounding them. They did find that in one of their monkeys with significant cerebellar damage due to stimulation that the threshold for evocation of motor cortex potentials by paravermal stimulation was increased by a factor of at least four from its initial, prestimulation level. Sances et $\mathrm{l}^{18}$ found that no substantial changes in cerebellar current were required to suppress the amplitude of the somato-sensory evoked potential in chimpanzees, examined over a four month period, that had been implanted with cerebellar stimulating equipment but not chronically stimulated. Davis $e t \boldsymbol{~}^{2}$ found no significant change in the electrode impedance in seven patients reexamined 8-16 months after initial implantation.

In our patient the amplitude of the stimulus artefact, an indirect measure of cerebellar current assuming the position of the electrodes does not change, dropped gradually on the left from its initial value of $3.8 \mathrm{mV}$ measured seven days after repositioning to $1.5 \mathrm{mV}$ nine months later.

The output characteristics of the implanted receiver in response to a change in load are complex. If a constant amplitude of RF signal is transmitted to the receiver and electrode impedance falls, the voltage applied across the electrode would tend to fall and the current would tend to increase slightly. Thus, a decline in the stimulus artefact from $3.8 \mathrm{mV}$ to $1.5 \mathrm{mV}$ would be consistent with a fall in the access resistance of the electrode and a consequent rise in the peak electrode current. Bench studies with a similar receiver in our laboratory indicated that under these circumstances peak electrode current would rise from $5 \mathrm{~mA}$ to a maximum of approximately $6.5 \mathrm{~mA}$. Over this same period, the stimulus artefact from the right electrode remained fairly stable at approximately $1.4 \mathrm{mV}$.

Despite encapsulation of the electrodes there was virtually no damage to the cerebellum of the patient described here following the implantation and presence of cerebellar electrodes in the posterior fossa for sixteen months. Capacitively-coupled, bipolar, alternating polarity stimulation which, at the very least, was applied in the continuous alternating $\stackrel{\odot}{\overparen{D}}$ mode for two months and the intermittent bilateral mode for two months at a charge density of $15.6, \mu \mathrm{C} / \mathrm{cm}^{2} /$ phase does not appear to have caused any significant damage. From the case described을 here and the other work reviewed it seems likely that much of the damage seen in the cerebellum after a period of chronic electrical stimulation is due to operative and mechanical trauma. Evidence from this study and the other studies on human and large animals suggests that, at approximately $15.6 \mu \mathrm{Cl}$ $\mathrm{cm}^{2} /$ phase, electrical stimulation of the cerebellum causes little if any damage. The effectiveness of electrical stimulation may be changed by encapsulation of the electrodes and this may be related partly to the length of time in situ and partly to the charge transferred. More information will be required before it can be established whether longer periods of stimulation lead to accumulative pathological effects. If long-term pathological changes do lead to a reduction in the therapeutic effect of stimulation the possible gains from reimplantation of the electrodes may need to be weighed against the potential hazards of repeated operations.

We thank Dr Lindsay McLellan and Dr Jolyon Oxley for permitting us to publish details of their patient. Mr Jason Brice performed both operations. The necropsy was performed by Dr JJ Lucey. The apparatus was supplied by Avery Laboratories Inc 
and purchased with a grant from the Medical Research Council of Great Britain with whom GDS Wright is the holder of a research fellowship. Dr Lindsay McLellan's helpful criticism of this article has been invaluable. Finally, we should like to thank Mrs M Dowling for typing the manuscript.

\section{References}

' Cooper IS, Upton ARM. Use of chronic cerebellar stimulation for disorders of disinhibition. Lancet 1978;1:595-600.

${ }^{2}$ Davis R, Barola-Romana G, Engle H. Chronic cerebellar stimulation for cerebral palsy-five year study. Acta Neurochir (Wein) 1980;Suppl. 30:317-32.

${ }^{3}$ Hambrecht FT. Neural prosthesis. Ann Rev Biophys Bioeng 1979;8:239-67.

4 Urich H, Watkins ES, Amin I, Cooper IS. Neuropathologic observations on cerebellar lesions in patients with epilepsy and motor disorders. In: Cooper IS, ed. Cerebellar Stimulation in Man. New York: Raven Press, 1978:145-59.

${ }^{5}$ Cooper IS, Amin I, Rikland M, Waltz JM, Poon TP. Chronic cerebellar stimulation in epilepsy. Arch Neurol 1976;33:559-70.

${ }^{6}$ Robertson LT, Dow RS, Cooper IS, Levy LF. Morphological changes associated with chronic cerebellar stimulation in the human. $J$ Neurosurg 1979;51:510 20.

${ }^{7}$ Cooper IS, Riklan M, Amin I, Cullinan T. A long-term follow-up study of cerebellar stimulation for the control of epilepsy. In: Cooper IS, ed. Cerebellar Stimulation in Man. New York: Raven Press, 1978:19-38.

${ }^{8}$ Dow RS. Summary and Evaluation of Chronic Cerebellar Stimulation in Man. Cooper IS, ed. New York:
Raven Press, 1978:207-12.

${ }^{9}$ Larson J, Sances A, Hemmy DC, Millar EA, Walsh PR. Physiological and histological effects of cerebellar stimulation. Appl Neurophysiol 1977/78;40:160-74.

${ }^{10}$ McLellan DL, Wright GDS, Renouf F. Calibration of clinical cerebellar and deep brain stimulation systems. J Neurol Neurosurg Psychiatry 1981;44:392-6.

${ }^{11}$ Norman RM, Sandry S, Corsellis JAN. The nature and origin of pathoanatomical change in the epileptic brain. In: Vinker PJ, Bruyn GW, eds. Handbook of Clinical Neurology, Vol 15, The Epilepsies. Amsterdam: North Holland Publishing Company, 1974: 611-20.

${ }^{12}$ Greenfield's Neuropathology, 3rd ed. Blackwood W, Corsellis JAN, eds. London: Edward Arnold, 1976:771-96.

${ }^{13}$ Reynolds EH. Chronic antiepileptic toxicity: a review. Epilepsia 1975;16:219-352.

${ }^{14}$ Brown WJ, Babb TL, Soper HV, Lieb JP, Ottino CA, Crandall PH. Tissue reactions to a long-term electrical stimulation of the cerebellum in monkeys. $J$ Neurosurg 1977;47:366-79.

15 Dauth GW, Defendini R, Gilman S, Kremzner L. Longterm surface stimulation of the cerebellum in the monkey. I. Light mircroscopic, electrophysiologic and clinical observations. Surgical Neurol 1977;7:377-84.

${ }^{16}$ Girvin JP. A review of basic aspects concerning chronic cerebral stimulation. In: Cooper IS, ed. Cerebellar Stimulation in Man. New York: Raven Press, 1978:1-12.

${ }^{17}$ Babb TL, Soper HV, Lieb JP, Brown WJ, Ottino CA, Crandall PH. Electrophysiological studies of longterm electrical stimulation of the cerebellum in monkeys. J Neurosurg 1977;47:353-65.

${ }^{18}$ Sances A, Larson S, Myklebust J, et al. Evaluation of electrode configurations in cerebellar implants. Appl Neurophysiol 1977-78;40:141-59. 